\title{
O Método Fenomenológico na Pesquisa sobre EMPREENDEDORISMO NO BRASIL
}

\author{
The Phenomenological Method in the Research on \\ Entrepreneurship in Brazil
}

\begin{abstract}
Antonio Carlos Gil
Professor do Programa de Pós-Graduação em Administração. Universidade Municipal de São Caetano do Sul. São Paulo, SP. Brasil. E-mail: acgil@uol.com.br
\end{abstract}

\section{Suely Percinio Moreira Silva}

Mestre em Administração. Universidade Municipal de São Caetano do Sul. São Paulo, SP. Brasil. E-mail: suelypercinio@gmail.com.br

\section{Resumo}

A maioria das pesquisas sobre o empreendedorismo tem sido realizada segundo a perspectiva positivista. Verifica-se, no entanto, tendência para sua investigação sob outros enfoques. Assim, elaborou-se o presente estudo, que tem como objetivos: 1) Discutir a aplicabilidade do método fenomenológico no estudo do empreendedorismo; 2) Analisar o "estado da arte" da investigação acerca do empreendedorismo sob esse enfoque. Trata-se de um ensaio fundamentado em contribuições teóricas e em relatos de pesquisas empíricas de cunho fenomenológico sobre empreendedorismo no Brasil. O método fenomenológico apresenta grande potencial para o estudo do empreendedorismo, pois permite que a ação empreendedora seja conhecida sob o ponto de vista do próprio empreendedor. Contudo, ainda é reduzido o número de pesquisas sobre empreendedorismo com a aplicação desse método. Recomenda-se aos pesquisadores que atentem para o potencial desse método para a compreensão do fenômeno empreendedor e que se disponham a investigá-lo sob a perspectiva dos próprios empreendedores.

Palavras-chave: Empreendedorismo. Método fenomenológico. Pesquisa.

\section{Abstract}

Most research on entrepreneurship has been performed according to the positivist perspective. It appears, however, a tendency for other approaches under investigation. This study was prepared in order to: 1) Discuss the applicability of the phenomenological method in the study of entrepreneurship; 2) Analyze the "state of the art" research on entrepreneurship in this light. It is a reasoned essay on theoretical contributions and empirical research reports phenomenological nature of entrepreneurship in Brazil. The phenomenological method has great potential for the study of entrepreneurship, as it allows know the entrepreneurial action from the point of view of the entrepreneur himself. However, it is reduced the number of entrepreneurship research on the application of this method. It is recommended that researchers who pay attention to the potential of this method for understanding the entrepreneur phenomenon and who are willing to investigate it from the perspective of the entrepreneurs themselves.

Keywords: Entrepreneurship. Phenomenological method. Research. 


\section{INTRODUÇÃo}

O empreendedorismo vem se constituindo como importante área de ensino e pesquisa em Administração. No currículo de muitos cursos de graduação em Administração, é possível observar que são ofertadas até mesmo disciplinas específicas voltadas ao empreendedorismo. Também são oferecidos cursos de pós-graduação na modalidade lato sensu destinados à capacitação e ao aperfeiçoamento de pessoal interessado em atuar nesse campo. Em alguns programas de mestrado e doutorado em Administração há linhas de pesquisa diretamente relacionadas ao empreendedorismo. Nos cursos de graduação em Administração, por sua vez, verifica-se um número cada vez maior de trabalhos de conclusão de curso e de iniciação científica que tem como objeto o empreendedorismo.

Nos eventos destinados a divulgar a produção científica em Administração vem sendo gradativamente incluída a área de empreendedorismo. Cabe considerar, ainda, que desde o ano 2000 vem sendo promovido o Encontro de Estudos Sobre Empreendedorismo e Gestão de Pequenas Empresas, que reúne relatos estudos e pesquisas realizados em todo o país. Verifica-se também a ampliação da quantidade de artigos sobre empreendedorismo publicados em periódicos.

Justifica-se o interesse pela investigação sobre empreendedorismo, pois este é reconhecido como fundamental tanto para o desenvolvimento econômico das nações como para a promoção de seres humanos (KELLEY; SINGER; HERRINGTON, 2012). Assim, papel importante é reservado à Ciência da Administração, já que lhe cabe não apenas proporcionar elementos para promover o aprendizado do empreendedorismo quanto desenvolver métodos e técnicas adequados para realizar de pesquisas empíricas.

O empreendedorismo como campo do conhecimento encontra-se em formação. Embora seja possível encontrar fundamentação teórica para esse campo do conhecimento já na década de 1950, graças aos trabalhos de Schumpeter (1954), a pesquisa empírica só se inicia no final do século XX, ou seja, após o início dos debates acerca das alternativas metodológicas aos preceitos positivistas de pesquisa que até então vinham orientando a pesquisa em Administração.

A pesquisa sobre empreendedorismo implica a consideração de múltiplos aspectos, tais como: ino- vação, criatividade, descoberta, invenção, liderança, cultura, decisão, visão de futuro, riscos, julgamento, valores, crenças e gestão de recursos humanos, materiais e financeiros. São aspectos que se tornam melhor compreendidos quando estudados do "lado de dentro", ou seja, do ponto de vista de seus atores. Daí a importância assumida pela adoção do enfoque interpretativista na investigação desses fenômenos. (DENZIN; LINCOLN, 1994)

Há diferentes modalidades de pesquisa de caráter interpretativista, sendo que as mais conhecidas são a pesquisa fenomenológica, a pesquisa etnográfica e a teoria fundamentada nos dados (grounded theory). Pesquisas realizadas sob esse enfoque correspondem a uma parcela significativa da produção científica em alguns campos do conhecimento, como Psicologia, Educação e Enfermagem, e vêm se tornando cada vez mais frequentes no campo da Administração.

Dentre as três principais modalidades de pesquisa de cunho interpretativista, a menos utilizada em Administração - e consequentemente na pesquisa sobre empreendedorismo - é a pesquisa fenomenológica. Embora esta modalidade de pesquisa já tenha sido considerada como importante promessa para a investigação nessa área do conhecimento (SANDERS, 1982), essa situação conduz, portanto, a algumas questões para investigação: Qual a aplicabilidade da pesquisa fenomenológica no campo do empreendedorismo? O que já se investigou sobre o empreendedorismo sob a perspectiva fenomenológica? Que procedimentos metodológicos foram adotados nessas pesquisas? Com vistas, pois, a proporcionar respostas a essas questões, realizou-se o presente estudo, que tem como objetivos: 1) Discutir a aplicabilidade do método fenomenológico no estudo do empreendedorismo; 2) Analisar o "estado da arte" da investigação acerca do empreendedorismo sob o enfoque fenomenológico no Brasil.

\section{Método}

O presente estudo pode ser definido como um ensaio apoiado em pesquisa bibliográfica e documental. Para tanto foram analisadas contribuições teóricas de filósofos e pesquisadores que se dedicaram à fundamentação do método fenomenológico no campo da Filosofia, bem como à sua transposição para o 
domínio das Ciências Sociais. Procedeu-se também à análise de relatos de pesquisas empíricas de cunho fenomenológico sobre empreendedorismo no Brasil.

Para viabilizar este estudo foram identificados relatos de pesquisa sobre empreendedorismo sob o enfoque fenomenológico apresentados em principais eventos ou publicados em periódicos científicos da área de Administração. Foram, pois, analisados todos os relatos de pesquisa sobre empreendedorismo apresentados nos eventos patrocinados pela Associação Nacional de Pós-graduação e Pesquisa em Administração - ANPAD, de 1998 a 2011, nos Encontros de Estudos sobre Empreendedorismo e Gestão de Pequenas Empresas - EGEPE, de 2000 a 2010 e nos Seminários de Administração, desde a introdução do empreendedorismo como área temática, ou seja, de 2005 a 2011. Foram também analisados os relatos de pesquisa sobre empreendedorismo publicados em periódicos da Área de Administração classificados nas categorias A e B do Sistema Qualis, de 2000 a 2011. Procedeu-se, então, à análise desses relatos, considerando a adequação de seus objetivos e dos procedimentos de coleta e análise de dados à investigação fenomenológica.

Embora haja uma tendência para desconsiderar os trabalhos apresentados em eventos em virtude de se referirem com frequência a pesquisas ainda não concluídas, estes foram abordados no presente trabalho em virtude do pequeno número de trabalhos publicados em periódicos. O que exigiu dos autores maiores considerações críticas na análise dos resultados.

\section{Aplicabilidade do Método Fenomenológico na Pesquisa sobre EMPREENDEDORISMO}

Como o primeiro objetivo do presente trabalho é o de discutir a aplicabilidade do método fenomenológico na pesquisa sobre o empreendedorismo, trata-se inicialmente nesta seção do reconhecimento da perspectiva interpretativista na pesquisa em Administração. A seguir, passa-se à apresentação dos fundamentos do método fenomenológico e à sua utilização no campo da Administração e, por fim, à discussão acerca da aplicabilidade desse método no campo do empreendedorismo.

\subsection{A Emergência do Interpretativismo na Pesquisa em Administração}

A Ciência da Administração constituiu-se num momento em que o positivismo alcançava significativo prestígio. Assim, as respostas às questões ontológicas, epistemológicas, metodológicas e éticas relativas à nova disciplina foram sendo procuradas em obras que emprestavam fundamento àquela orientação. Os primeiros pesquisadores no campo da Administração eram engenheiros, que tinham como referencial para realização de pesquisas científicas os métodos ciências naturais, valorizados pelo Positivismo. Como o modelo positivista de ciência permaneceu hegemônico durante os três primeiros quartéis do século $\mathrm{XX}$, os pesquisadores no campo da Administração nesse período sentiram-se seguros em relação aos procedimentos metodológicos adotados nas pesquisas. A ponto de até recentemente alguns dos mais conhecidos manuais de pesquisa em administração (COOPER; SCHINDLER, 2003; ZIKMUND, 2003) restringirem os possíveis delineamentos de pesquisa aos estudos experimentais, estudos observacionais e levantamentos de campo, os mais valorizados na perspectiva positivista.

Embora a hegemonia positivista ainda seja evidente no campo da Administração, verifica-se a ampliação do número de pesquisas que adotam a perspectiva interpretativista. Nestas pesquisas a ênfase, mais do que na procura da objetividade, está na maneira como seus sujeitos interpretam a realidade que vivenciam. Diversos trabalhos apresentados em eventos promovidos pela Associação Nacional de Pesquisa em Pós-Graduação em Administração e Contabilidade analisam o crescimento dessas pesquisas. (SILVEIRA; FISCHER; OLIVIER, 2010; BOAVA; MACEDO, 2010; VIEIRA, 2009)

Essa emergência de estudos de cunho interpretativista indica uma tendência para a aceitação de pesquisas voltadas ao conhecimento dos fenômenos administrativos não como "coisas", conforme a perspectiva positivista expressa por Émile Durkheim (1999). Indica ainda a aceitação por parte de muitos pesquisadores de que o propósito da investigação científica não é unicamente o de conhecer a realidade vivenciada por essas pessoas, mas também de modificá-la. Essa situação torna-se bastante evidente nos campos em que os integrantes das populações em estudo são pessoas que apresentam carências. Um desses campos é o do 
empreendedorismo, sobretudo porque com frequência cada vez maior são identificados grupos de empreendedores constituídos por pequenos empresários, comunidades carentes, minorias socialmente fragilizadas e portadores de necessidades especiais. Daí, então, a realização de pesquisas sob a perspectiva da etnografia, da grounded theory e da fenomenologia.

\subsection{Método Fenomenológico}

As origens da fenomenologia podem ser encontradas na segunda metade do século XIX, nos estudos de Franz Bretano (1995) acerca da intencionalidade. Mas foi graças aos trabalhos de Edmund Husserl (1986) que se tornou possível falar em método fenomenológico. Para este autor, sua finalidade era a de fornecer os instrumentos básicos para a constituição de uma filosofia rigorosamente científica. E muito do desenvolvimento da fenomenologia desenvolvida na primeira metade do século XX orientou-se no sentido de constituir um método rigorosamente filosófico. Daí os trabalhos de autores como Martin Heidegger (2005), Jean Paul Sartre (1997) e Maurice Merleau-Ponty (2006).

O método fenomenológico é essencialmente filosófico. Seu objetivo é o estudo do fenômeno, isto é, das coisas em si mesmas e não do que é dito sobre elas. O que se busca alcançar com esse método é a consciência do sujeito mediante a expressão de suas experiências internas. Para a fenomenologia, um objeto é como o sujeito o percebe, devendo, portanto, ser estudado sem interferência de qualquer regra de observação. Assim, tanto um objeto concreto quanto uma sensação, uma recordação ou uma crença, devem ser estudados tal como o são para o espectador.

Embora a preocupação fundamental dos autores citados tenha sido a de constituir um método filosófico, a fenomenologia despertou também a atenção de psiquiatras interessados na busca de procedimentos alternativos para o tratamento de seus pacientes. Assim, Karl Jaspers (1979, ed. original 1913) propôs a utilização da fenomenologia no campo da psiquiatria. Graças ao trabalho de Jaspers e de psiquiatras e psicólogos que o sucederam, o método fenomenológico tornou-se um dos mais importantes no campo da psicologia clínica.
Foi só na segunda metade do século passado que a fenomenologia passou a ser encarada como método de investigação científica. Percebeu-se que a fenomenologia poderia auxiliar não apenas para tornar a filosofia uma ciência rigorosa, mas também para investigar aspetos da existência para os quais os procedimentos tradicionais das ciências humanas não se mostraram suficientes. Sobretudo para a investigação da experiência vivida no mundo do dia-a-dia das pessoas. O método fenomenológico passou, então, a ser reconhecido como adequado para proporcionar fundamentação às chamadas pesquisas qualitativas. Como consequência, muitas pesquisas em campos como o da Psicologia, Educação, Sociologia e Enfermagem passaram a ter como fundamento o método fenomenológico.

Ao longo do tempo, diferentes correntes de pensamento fenomenológico foram se definindo $e$, buscando cobrir a lacuna deixada pelos criadores da fenomenologia, diversos autores se empenharam em esclarecer os procedimentos a serem adotados na pesquisa fenomenológica. Assim, foram propostos diferentes modelos para a investigação fenomenológica, que se consolidaram em função da orientação filosófica de seus autores. Em relação aos procedimentos sugeridos para a investigação, podem ser identificadas três correntes. A primeira é a da Fenomenologia Descritiva, derivada diretamente das ideias de Edmund Husserl, que teve seu início com o estudo pioneiro de Van Kann (1959) e se concentra na Duquesne University, em Pittsburg (USA). A segunda é a Escola Hermenêutica, que tem como principal fundamento os trabalhos de Martin Heidegger (2002). A terceira, por fim, que pode ser considerada uma escola híbrida, é Escola, de Utrecht, caracterizada como descritiva e interpretativa, tem como principal expoente Van Manen (1990).

Há muitos pontos de encontro entre as tendências. As três abordagens enfatizam mais a descrição do que a explicação. Reconhecem a necessidade da suspensão das crenças prévias com vistas a descobrir a estrutura essencial do fenômeno. Valorizam o uso da variação imaginativa para iluminar os temas ou essências durante a análise dos dados. Consideram que o foco de qualquer investigação fenomenológica está com o fenômeno em si não na experiência subjetiva dos participantes. 
Autores vinculados a essas correntes têm apresentado diferentes modelos para a condução de pesquisa. O que todos têm em comum é a aceitação de que o material para análise deriva de manifestações dos sujeitos acerca da experiência vivida, obtidas principalmente mediante entrevistas ou relatos escritos. Já a análise pode ocorrer de diferentes maneiras; até mesmo, segundo Van Manen (1990), mediante a invenção de uma abordagem. Assim, como uma tentativa de sintetizar contribuições de autores vinculados às correntes mencionadas, foi elaborado o Quadro 1, que apresenta as etapas a serem seguidas no método fenomenológico, segundo diferentes autores. Van Kaan (1959), Colaizzi (1978) e Giorgi (1985) alinham-se à Fenomenologia Descritiva; Dickelmann, Allen e Tanner à Fenomenologia Hermenêutica (1989); e Van Manen (1990) é o principal expoente da Escola de Utrecht. Cabe considerar, no entanto, que Van Manen não define seu método como uma sequência de etapas, mas de abordagens.

\begin{tabular}{|c|c|c|c|c|c|}
\hline $\begin{array}{c}\text { Autores / } \\
\text { EtAPAS }\end{array}$ & $\begin{array}{c}\text { Dickelman Allen } \\
\text { \& TanNer }\end{array}$ & Colaizzi & VAN KAAM & GIORGI & Van Manen \\
\hline 1 & $\begin{array}{l}\text { Análise do texto } \\
\text { como um todo }\end{array}$ & $\begin{array}{l}\text { Leitura integral } \\
\text { das descrições }\end{array}$ & $\begin{array}{l}\text { Listagem e grupa- } \\
\text { mento preliminar } \\
\text { das expressões. }\end{array}$ & $\begin{array}{l}\text { Leitura geral da des- } \\
\text { crição para obtenção } \\
\text { de uma visão geral }\end{array}$ & $\begin{array}{l}\text { Exame do texto como } \\
\text { um todo visando captar } \\
\text { os significados (abor- } \\
\text { dagem holística) }\end{array}$ \\
\hline 2 & $\begin{array}{l}\text { Resumo das seções } \\
\text { do texto e identifica- } \\
\text { ção das categorias }\end{array}$ & $\begin{array}{l}\text { Formulação de } \\
\text { significados para } \\
\text { as assertivas }\end{array}$ & $\begin{array}{c}\text { Redução das } \\
\text { expressões dos } \\
\text { participantes em } \\
\text { termos expressivos }\end{array}$ & $\begin{array}{l}\text { Discriminação de } \\
\text { unidades de sentido }\end{array}$ & $\begin{array}{l}\text { Destaque das frases que } \\
\text { parecem essenciais para } \\
\text { a experiência em estudo } \\
\text { (abordagem seletiva) }\end{array}$ \\
\hline 3 & $\begin{array}{l}\text { Análise do texto com } \\
\text { base nas categorias }\end{array}$ & $\begin{array}{l}\text { Organização } \\
\text { de significados } \\
\text { em temas }\end{array}$ & $\begin{array}{l}\text { Eliminação dos ele- } \\
\text { mentos não ineren- } \\
\text { tes ao fenômeno que } \\
\text { está sendo estudado. }\end{array}$ & $\begin{array}{l}\text { Articulação dos insights } \\
\text { das unidades de sentido }\end{array}$ & $\begin{array}{c}\text { Exame de cada sentença } \\
\text { para definir o que revelam } \\
\text { acerca da experiência } \\
\text { (abordagem detalhada) }\end{array}$ \\
\hline 4 & $\begin{array}{l}\text { Identificação de temas } \\
\text { relacionais no texto }\end{array}$ & $\begin{array}{l}\text { Organização dos } \\
\text { temas numa des- } \\
\text { crição exaustiva } \\
\text { do fenômeno }\end{array}$ & $\begin{array}{l}\text { Redação de uma } \\
\text { identificação e } \\
\text { descrição hipotética } \\
\text { do fenômeno }\end{array}$ & $\begin{array}{l}\text { Síntese das unidades de } \\
\text { sentido numa declaração } \\
\text { consistente em relação à } \\
\text { experiência dos sujeitos }\end{array}$ & \\
\hline 5 & $\begin{array}{l}\text { Geração de padrões } \\
\text { constitutivos }\end{array}$ & $\begin{array}{c}\text { Formulação } \\
\text { da descrição } \\
\text { exaustiva do } \\
\text { fenômeno numa } \\
\text { declaração de } \\
\text { sua estrutura }\end{array}$ & $\begin{array}{l}\text { Aplicação da des- } \\
\text { crição hipotética a } \\
\text { casos selecionados } \\
\text { aleatoriamente }\end{array}$ & & \\
\hline 6 & $\begin{array}{l}\text { Validação da análi- } \\
\text { se por pessoas que } \\
\text { não fazem parte } \\
\text { da equipe de }\end{array}$ & $\begin{array}{l}\text { Validação da } \\
\text { análise pelo } \\
\text { retorno a cada } \\
\text { participante }\end{array}$ & $\begin{array}{c}\text { Com base nas } \\
\text { operações reali- } \\
\text { zadas na etapa } \\
\text { anterior, considerar } \\
\text { a identificação final }\end{array}$ & & \\
\hline 7 & $\begin{array}{l}\text { Elaboração do } \\
\text { relatório final }\end{array}$ & & & & \\
\hline
\end{tabular}

Quadro 1: Etapas da pesquisa fenomenológica segundo diferentes autores

Fonte: Van Kaam (1959), Colaizzi (1978), Giorgi (1985), Dickelman, Allen e Tanner (1989) e Van Manen (1990)

\subsection{A Utilização do Método Fenomenológico na Administração}

A Administração foi concebida em suas origens como uma área do conhecimento caracterizada pelo desempenho das funções de planejar, dirigir, organizar e controlar. Seus fundadores tiveram a pretensão de estudar os aspectos mecânicos da produção. Mas à medida que foi se desenvolvendo, a Administração mostrou-se muito mais complexa do que seus criadores imaginavam. Sobretudo quando identificaram o lado humano da empresa e a complexidade do 
comportamento dos empregados (EHRICH, 2005). Daí o interesse de muitos pesquisadores em realizar pesquisas qualitativas. O que fica evidenciado com o crescimento do número de pesquisas realizadas sob a perspectiva interpretativista nos últimos anos.

Dentre essas pesquisas, tem sido mais frequentes as realizadas sob a perspectiva do interacionismo simbólico, da etnografia e da grounded theory. Relatos de pesquisa em que se adotou o método fenomenológico ainda são raras nos diferentes campos da Administração.

Num artigo clássico, Patrícia Sanders (1982) apresenta a fenomenologia como uma nova maneira de encarar os estudos organizacionais, como uma nova estrela no horizonte da pesquisa organizacional. Essa autora chega até mesmo a propor um modelo para realização de pesquisas na área, mas reconhece a dificuldade para encontrar estudos fenomenológicos na pesquisa em Administração. Ehrich (2005) também constata a parca utilização do método fenomenológico na Administração, mas reconhece seu potencial para investigação nesse campo, posto que a Administração, mais do que uma técnica de controle é um processo e prática em que a dimensão humana é muito forte.

Gibson e Hanes (2003), com base em extenso estudo em bases de dados no período de 1998 a 2003, constataram a quase ausência de estudos fenomenológicos no campo do desenvolvimento de recursos humanos. Identificaram apenas quatro estudos publicados em periódicos e nove apresentados em eventos; um deles elaborado por brasileiros (TEIXEIRA; GOMES, 2000). Mas consideram a fenomenologia como metodologia essencial para possibilitar uma compreensão mais completa da natureza holística e da complexidade de experiências que são relevantes à prática desse ramo da administração.

Moreira (2002) constata um incremento na utilização do método fenomenológico nas pesquisas em administração, mas com base nos relatos apresentados, conclui que muitos pesquisadores não sabem definir exatamente o que é fenomenologia. Gil (2003), por sua vez, considera que a adoção do enfoque fenomenológico na pesquisa em Administração nem sempre decorre da percepção por parte dos pesquisadores do reconhecimento de seu alcance epistemológico, mas sim do interesse em fazer pesquisa qualitativa. Já Carvalho e Vergara (2002) consideram que o enfoque positivista tem imposto sua supremacia aos pesquisadores brasileiros no campo da Administração, desencorajando-os a conduzir pesquisas com orientação fenomenológica.

Thiry-Cherques (2004) também considera o método fenomenológico adequado à pesquisa em Administração, alegando que este possibilita a tematização de conceitos e propriedades com a mesma facilidade com que se tematiza um objeto material, sem a necessidade de explicar a que o conceito se aplica ou a que a propriedade se refere historicamente. Paiva Júnior (2008), por sua vez, considera a abordagem fenomenológica adequada para o pesquisador organizacional acessar os fenômenos percebidos, relembrados $e$ desejados do ambiente da organização na sua condição de significados e estruturas estabelecidos como experiências humanas vividas.

Mas ainda é reduzido o número de pesquisas fenomenológicas em Administração realizadas no Brasil. Essa situação é evidenciada no trabalho de Silveira, Fisher e Olivier (2010), que indica apenas 26 artigos referentes a trabalhos de pesquisa com enfoque fenomenológico publicados nos anais dos principais eventos e em periódicos de Administração, entre 1997 e 2008. Ressalte-se, ainda, que a maioria dos artigos publicados em periódicos também foi apresentada em eventos.

Embora o método fenomenológico mostre-se útil para a investigação em Administração, não pode ser visto como substituto dos métodos tradicionais. Não pode ser utilizado, por exemplo, quando o propósito do investigador é promover generalizações empíricas ou identificar fatores que determinam a ocorrência dos fenômenos. É utilizado apropriadamente quando se deseja conhecer a experiência vivida dos atores sociais. O campo privilegiado da Administração para sua utilização é, pois, a do comportamento organizacional. Mas também pode ser utilizado em outros campos, como o do comportamento do consumidor ou mesmo da gestão da produção. Desde que o pesquisador tenha como propósito conhecer a experiência vivida, mais do que conceituá-la; que tenha interesse em refletir acerca dos temas essenciais que caracterizam o fenômeno; e em promover uma investigação equilibrada, que considere tanto a parte como o todo. (VAN MANEN, 1990) 


\subsection{O Potencial do Método Fenomenológico no Estudo do Empreendedorismo}

As primeiras pesquisas científicas no campo do empreendedorismo apareceram na década de 1990. Foram constituídas principalmente por surveys, que utilizavam questionários e escalas de atitude para obtenção dos dados. Em 2004, Davidson edita a primeira obra que trata sistematicamente da pesquisa sobre empreendedorismo. Embora reconhecendo a importância da pesquisa qualitativa, esse autor pouco esclarece acerca dessa modalidade de pesquisa, alegando pouca familiaridade com os procedimentos a ela associados. Esse trabalho, que é um dos mais citados nas pesquisas sobre empreendedorismo não trata especificamente dos delineamentos de pesquisa qualitativa e nada informa acerca do método fenomenológico.

Mas já se constata uma tendência para investigar o fenômeno empreendedor mediante a utilização de métodos qualitativos, Uma importante contribuição foi dada pela edição do livro organizado por Neergard e Ulhoi (2007), que trata especificamente dos métodos qualitativos na pesquisa sobre empreendedorismo. Seus colaboradores tratam de diferentes modalidades de pesquisa qualitativa: pesquisa etnográfica (JOHNSTONE, 2007), grounded theory (MÄKELÄ; TURCAN, 2007), pesquisa-ação (LEITCH, 2007) histórias de vida (McKENZIE, 2007). Um dos capítulos, elaborado por Berglund (2007) trata especificamente da pesquisa fenomenológica.

Berglund faz uma análise crítica das pesquisas sobre o empreendedorismo, ressaltando que os questionários e as escalas de atitude, que são instrumentos mais utilizados, tendem a expressar apenas mecanismos cognitivos relativamente estáveis. Propõe, então, a utilização do método fenomenológico nessas pesquisas. Dentre suas alegações está a de que a pesquisa fenomenológica, por voltar-se para a experiência vivida dos empreendedores, possibilita a compreensão de suas motivações, aspirações e temores, bem como das dificuldades percebidas no processo empreendedor e do significado atribuído à abertura do próprio negócio. Assim, considera que o método fenomenológico consiste num meio estruturado para investigar como conceitos populares e eventos comuns na vida dos empreendedores, como a descoberta de oportunidades e a assunção de riscos oportunidades, são vivenciados e transformados em ação.

Cope (2005) ressalta a riqueza dos dados obtidos na pesquisa fenomenológica, já que esta busca conhecer aquilo que aflora à consciência dos empreendedores. Além disso, considera ser um método que respeita e valoriza as experiências dos participantes, priorizando as suas interpretações em vez de tentar confirmar ou refutar proposições teóricas prévias. Isto porque o procedimento mais utilizado para coleta de dados nessa modalidade de investigação é a entrevista não estruturada, não diretiva, em que o entrevistador não age como detentor de maior poder ou conhecimento que o entrevistado em relação à sua própria experiência.

Como a entrevista é conduzida com base numa pergunta norteadora, habilita o sujeito a expressar o que está em sua mente e a explorar suas experiências da maneira que julgar mais conveniente, já que é estimulado a contar sua própria história, livre do constrangimento de um conjunto de questões restritivas e inibidoras. (THOMPSON et al., 1989)

Para Anderson e Starnawska (2008), o paradigma positivista envolve um paradoxo: como analisar um fenômeno que não pode ser devidamente definido? Como consequência, muitas das investigações desenvolvidas segundo esse enfoque são fragmentárias $e$ incidem sobre aspectos estritos de empreendedorismo. Assim, pode haver muito mais riqueza quando as próprias pessoas esclarecem acerca do para elas que significa empreender. Por essa razão, esses autores consideram que a fenomenologia - assim como as demais metodologias interpretativistas - pode representar uma nova lente para enfocar o empreendedorismo. Consideram, também, que se a metodologia positivista contribui para ver as coisas como peças de um puzzle, a fenomenologia possibilita fornecer uma visão geral de como combiná-las.

Lowder (2009) considera que a maioria dos fatores de sucesso empresarial está diretamente relacionada às experiências humanas do empreendedor, e define a abordagem operativa dos atores, que é fundamentada na teoria dos sistemas, como mais adequada para investigação do empreendedorismo. Assim, a metodologia fenomenológica seria a mais bem-sucedida para os pesquisadores que se decidem por essa abordagem, porque proporcionaria recursos 
para gerar com flexibilidade um conjunto de dados mais rico viável para produzir resultados significativos.

\section{Análise das Pesquisas Fenomenológicas SOBRe EMPREENDEDORISMO NO BRASIL}

As pesquisas realizadas sob o enfoque fenomenológico no Brasil ainda são em pequeno número. Basta considerar que dentre os trabalhos apresentados nos seis Encontros de Estudos Sobre Empreendedorismo e Gestão de Pequenas Empresas-EGEPEs, realizados de 2000 a 2010, foram localizados apenas quatro referentes à realização de pesquisas sobre empreendedorismo conduzidas sob o enfoque fenomenológico. Dentre os trabalhos apresentados nos eventos patrocinados pela Associação Nacional de Pesquisa e Pós-Graduação em Administração - ANPAD até 2011 foram localizados apenas quatro. Nos Seminários da Administração da FEA-USP - SEMEADs foram localizados três trabalhos. Nos Simpósios de Administração da Produção, Logística e Operações Internacionais - SIMPOIs, que desde 2001 apresentam uma área temática específica para trabalhos sobre empreendedorismo, não foram localizados trabalhos com essas características. Dentre os trabalhos publicados em periódicos científicos nacionais da Área de Administração classificados como A e $\mathrm{B}$, foram localizados apenas quatro que se referem a pesquisas fenomenológicas no campo do empreendedorismo.

\subsection{Trabalhos Apresentados em Eventos Promovidos pela ANPAD}

Dentre os trabalhos apresentados nos eventos patrocinados pela ANPAD, de 1998 a 2008, quatro referem-se a ensaios que tratam do método fenomenológico e quinze a pesquisas fundamentadas nesse método. Dos quatro ensaios, um trata da aplicação do método fenomenológico ao estudo do empreendedorismo e das quinze pesquisas, apenas três têm como objeto o empreendedorismo, e são analisados a seguir.

Rodrigues e Vieira (2004) realizaram uma pesquisa com o objetivo colaborar com a percepção do processo sociocultural de formação da ação empreendedora pelo qual as pessoas organizam seus sonhos, atitudes ou necessidades de empreender.
Para tanto utilizaram entrevistas semiestruturadas e histórias de vida e também brainstorming com um dos participantes. Considere-se que o brainstorming não constitui procedimento dos mais adequados à pesquisa fenomenológica, já que sua maior riqueza está na possibilidade de favorecer a reflexão acerca do tema proposto, desfavorecendo, portanto, a obtenção de dados em estado pré-reflexivo.

Paiva Júnior (2005) apresentou trabalho cujo objetivo foi o de compreender o sentido da ação de criação e desenvolvimento de negócios sob a perspectiva de seis dirigentes de empresas de base tecnológica da Região Metropolitana do Recife. O trabalho visou esclarecer à seguinte questão: Qual o significado da identidade cultural do empreendedor no sentido da sua busca pelo desenvolvimento local? Da análise das respostas às entrevistas surgiram as seguintes unidades de significados que expressam a vinculação da identidade cultural do empreendedor com sua disposição para incrementar o desenvolvimento local: memória nacional despojada, credibilidade na contramão do embuste; reação à mendicância institucional; superação do individualismo do brasileiro, tradições, símbolos e o jeitinho brasileiro; criação empresarial e cultura popular; laços afetivos, cultura regional $e$ desenvolvimento local. Um importante dado desta pesquisa é a utilização da proposta de Schütz, que representa a primeira grande contribuição em prol da utilização do método fenomenológico na investigação em ciências sociais.

Boava, Macedo e Lopes (2006) apresentaram os resultados de uma pesquisa fenomenológica com cinco empresários da Incubadora Internacional de Empresas de Base Tecnológica da Universidade Estadual de Londrina. O fenômeno-problema dessa pesquisa foi assim definido: $\mathrm{O}$ que revelam os discursos de empresários incubados sobre empreendedorismo? A pesquisa iniciou-se com a elaboração de uma proposição aos relatores, nos seguintes termos: 1) O que é, para você, empreender? 2) O que significa, para você, empreendedorismo? 3) Descreva e comente aspectos de sua vivência como empresário incubado relacionado ao desenvolvimento de sua capacidade empreendedora que considere mais significativos e marcantes e 4) Quais as causas que o levaram a tornar-se empresário? Os resultados da pesquisa indicam que os empreendedores, reconhecem a importância e influência da 
inovação como instrumento para realização plena de suas potencialidades empreendedoras, mas que, embora circundados por um ambiente empreendedor, não incorporam o discurso do universo do empreendedorismo em seus relatos, nem fazem uma representação social dele.

Boava e Macedo (2006) apresentaram também um ensaio sobre a essência do empreendedorismo, a partir do estado de conhecimento de dimensão ontológica do fenômeno empreendedor, como forma de gerar resultados capazes de contribuir para uma nova forma de sua compreensão. Os autores concluem que a essência do empreendedorismo é a liberdade, que não está contida nela mesma, mas sim no âmbito do ser que empreende. Não se trata, portanto, da possibilidade que o empreendedor tem de agir conforme queira, mas sim da potencialidade deste.

\subsection{Trabalhos Apresentados nos EGEPEs}

Dentre os trabalhos apresentados em EGEPEs, o mais antigo é o de Paiva Jr., Mello e Gonçalves (2005), que analisa o fenômeno empreendedor sob a perspectiva de dirigentes de empresas de base tecnológica da Região Metropolitana do Recife, cujos dados foram obtidos a partir da pergunta norteadora: De que maneira os relacionamentos do empreendedor se consolidam pela sua credibilidade e adaptabilidade na vivência de negócios? Este trabalho origina-se de uma tese de doutorado e, diferentemente da maioria das pesquisas fenomenológicas, que fundamentam em relatos orais dos sujeitos, os autores indicam que para garantir a qualidade e confiabilidade dos dados foram utilizadas também notas de campo e observações de documentos escritos pelos dirigentes.

Oliveira (2008) apresentou um estudo que teve como objetivo identificar saberes primordiais à criação e ao desenvolvimento de negócios na perspectiva de dirigentes de perfil empreendedor de empresas de base tecnológica da Região Metropolitana do Recife. Este estudo baseou-se na mesma tese que deu origem ao trabalho de Paiva Jr., Mello e Gonçalves (2005) e numa dissertação elaborada por Chaves (2006) a partir de um caso. $\mathrm{O}$ autor também indica que os dados foram analisados mediante análise de conteúdo, conforme orientações de Bardin (1997). Ressalte-se que a adoção desse tipo de procedimento não é comum em pesquisas fenomenológicas, já que os procedimentos definidos por essa autora preveem logo na primeira fase analítica a formulação de hipóteses, o que dificulta a redução fenomenológica definida por Husserl.

Nesse mesmo evento, Boava e Macedo (2008) apresentaram um trabalho que, embora original, foi elaborado com dados obtidos na mesma pesquisa que subsidiou o trabalho apresentado no EnANPAD (BOAVA; MACEDO; LOPES, 2006), referente a empresários da Incubadora de Base Tecnológica de Londrina.

Macedo Ichikawa e Boava (2008) apresentaram também um ensaio em que discutem a utilização do tipo ideal na pesquisa sobre empreendedorismo. Com fundamento na obra de Alfred Schütz (2004), concluem que o tipo ideal poderá constituir um instrumento para compreensão aprofundada da realidade empreendedora, uma vez construído a partir da objetivação de vários significados subjetivos. E que poderá também contribuir para a consolidação da epistemologia do empreendedorismo.

\subsection{Trabalhos Apresentados nos SEMEADs}

No seminário realizado em 2008, Boava e Macedo apresentaram trabalho referente aos significados que os empresários atribuem à sua vivência empreendedora. Trabalho este que se valeu também dos dados obtidos de empresários da Incubadora de Base Tecnológica de Londrina (INTUEL), que subsidiou artigos apresentados no XXX ENANPAD e no V EGEP (BOAVA; MACÊDO, 2008). Nesse mesmo seminário, Macêdo e Boava (2008a) apresentaram relato de pesquisa com o objetivo de analisar a relação existente entre empreendedor e reconhecimento social a partir da ótica dos próprios empreendedores. Para tanto foram realizadas entrevistas semi-estruturadas com seis empreendedores participantes do programa de incubação desenvolvido pela Incubadora Tecnológica de Maringá.

Battistella et al. (2011) elaboram uma pesquisa visando compreender o significado da experiência vivida pelos gestores/proprietários ao falir suas organizações, procurando descrever seus processos gestacionais $e$ encontrar as essências da falência e seus ensinamentos. Para a obtenção dos dados foram realizadas entrevistas em profundidade com dois gestores da cidade de Santa Maria que passaram pelo processo falimentar. 


\subsection{Trabalhos Publicados em Periódicos Científicos}

O primeiro trabalho relativo a uma pesquisa fenomenológica sobre empreendedorismo publicada num dos periódicos compulsados foi o de Macedo e Boava (2009). A pesquisa teve como objetivo investigar os significados que empresários incubados na Incubadora Tecnológica de Maringá atribuem a sua ação. Para tanto foram realizadas entrevistas semi-estruturadas com seis empresários. Os dados foram analisados segundo a abordagem fenomenológica de Sanders (1982), proposta para a investigação no campo organizacional. A análise dos dados coletados indica que os empresários incubados relacionam sua vivência na incubadora de empresas com quatro unidades temáticas: oportunidade de parcerias, credibilidade no mercado, conhecimento técnico administrativo e estrutura física. A pesquisa também conduz à constatação de que os empresários atribuem à incubadora de empresas o papel de catalisadora do processo de desenvolvimento da ação empreendedora.

Vilela (2010) elaborou um trabalho com o objetivo de demonstrar como a Feira Brasileira de Moda Íntima (FEVEST) - do Arranjo Produtivo Local (APL) de confecções de Nova Friburgo representa um "fenômeno de marketing" que agrega iniciativas empreendedoras e de inovação. Poderia ser caracterizado como um estudo de caso orientado fenomenologicamente, já que o autor se preocupou com a obtenção de múltiplas fontes de evidência. Tanto é que foram realizadas 15 entrevistas formais, 31 entrevistas informais, além de depoimentos diversos e observação participante. Ao final são identificados "clusters de significados", mas não é apresentada uma síntese integradora.

Bazanini e Zanuto (2011) realizaram pesquisa com o objetivo e identificar as inovações e o empreendedorismo decorrentes das principais estratégias empregadas pela Ford do Brasil no projeto e lançamento do veículo EcoSport, em 2003. Os autores indicam ter utilizado como referencial teórico os pressupostos da teoria da Resource Based View (RBV) e as estratégias propostas pela Escola Empreendedora. O que não se mostra coerente com o método fenomenológico, que requer a supressão de qualquer concepção prévia acerca do fenômeno a ser investigado. Também não se mostra coerente com o método o procedimento adotado para coleta de dados, posto que foi realizada uma primeira entrevista com um especialista em mercado, que serviu para elaboração de roteiro para entrevistas subsequentes, realizadas com executivos da empresa e vendedores de concessionárias de automóveis próprios e concorrentes.

Silva (2006) conduziu uma pesquisa com o objetivo de compreender as experiências vividas da relação trabalho e família, com duas mulheres que são proprietárias de lojas nos Shopping Center do município de Itajaí. Embora a autora tenha indicado que a seleção da amostra foi definida pelo critério de saturação amostral. A análise dos dados indica o surgimento de três núcleos temáticos: mulher empreendedora, relação trabalho e família e influência família no trabalho. Os resultados, no entanto, não conduzem a uma síntese. A autora reconhece as deficiências do estudo, decorrentes da dificuldade em agendar as entrevistas com as mulheres empreendedoras devido à carga horária e outras funções exercidas por elas.

\section{Discussão dos Resultados}

Da análise dos dados depreende-se que embora seja significativa a quantidade de pesquisas sobre empreendedorismo no Brasil, ainda são poucas as que adotam o método fenomenológico. Esta situação não se mostra muito discrepante em relação à produção no campo da Administração de modo geral. Ocorre, porém, que o empreendedorismo constitui uma das áreas em que o método fenomenológico mais se ajusta. Isso porque a motivação para empreender, assim como o comportamento adotado com vistas à obtenção de sucesso na criação de um negócio, corresponde a uma das expressivas manifestações do ser humano; pelo menos como homo economicus. Assim, seria razoável esperar uma quantidade maior de pesquisas realizadas sob esse enfoque.

Embora tenham sido consultados trabalhos apresentados nos principais eventos ou publicados nos mais importantes periódicos de Administração, isto não significa que tenha sido considerada toda a produção científica sobre empreendedorismo no Brasil. Até mesmo porque os autores de modo geral encontram dificuldades para publicar trabalhos originados de pesquisas qualitativas. Não apenas no Brasil, mas também em países com maior tradição em pesquisa no campo 
do empreendedorismo. Considere-se, a propósito, o trecho, em tradução livre, de uma comunicação apresentada na Conferência Internacional do International Council for Small Business World, realizada em Halifax em 2010. Essa comunicação é produto de uma mesa de discussão constituída por Louis Jacques Filion, Leo-Paul Dana, Pierre-André Julien, José M. Veciana, Tor Aase Johannessen e Matthias G. Raith, alguns dos mais renomados autores no campo do empreendedorismo:

A pesquisa qualitativa tem nos proporcionado
mais teoria sobre empreendedorismo do que
a pesquisa quantitativa. Adam Smith deu-nos
a teoria com base em pesquisa qualitativa.
O mesmo é verdadeiro para Joseph Schum-
peter. A pesquisa qualitativa dá-nos as teorias,
mas os estudos quantitativos são mais fáceis de
serem publicados. Portanto, estamos diante de
um dilema. Devemos almejar a facilidade da
publicaçãode estudos quantitativos, ou deve-
mos enfrentar o desafio maior da construção da
teoria com métodos quantitativos? (FILION, et
al., 2010, p. 2 tradução nossa)

Considere-se, ainda, que dentre os 15 trabalhos identificados neste trabalho, alguns foram elaborados com base em resultados de uma mesma pesquisa. Diversos autores, por sua vez, são coautores em outros trabalhos. Donde se infere não apenas que o número de pesquisas sobre empreendedorismo realizadas sob o enfoque fenomenológico ainda é pequeno em nosso país, mas também que é diminuto o número de pessoas empenhadas nessa modalidade de pesquisa em nosso país.

Cabe ressaltar, também, que a adoção dos procedimentos metodológicos em alguns dos trabalhos analisados é crítica. Como foi verificado, em alguns desses trabalhos foram utilizadas de técnicas de coleta ou de análise de dados que não estão entre as mais adequadas para a investigação fenomenológica, como formulário, brainstorming e análise de conteúdo. O que não significa que a inovação não possa ser admitida na investigação fenomenológica. De fato, não existem normas rígidas para orientar a condução de pesquisas fenomenológicas, como ocorre nas pesquisas experimentais e nos levantamentos. Daí porque nas pesquisas fenomenológicas o pesquisador tem muito mais liberdade para definir os procedimentos a serem adotados para coleta de dados. Mas torna-se necessário analisar criticamente esses procedimentos com vistas ao aprimoramento de instrumentos válidos para a pesquisa fenomenológica. Como fez Mairing (2003), ao desenvolver um modelo de análise qualitativa que pode ser aplicado a estudos de casos e provavelmente a estudos fenomenológicos.

Constata-se também a preocupação de alguns autores em justificar a adoção do método fenomenológico na pesquisa. De fato, a demonstração do quadro de referência que fundamenta o delineamento da pesquisa é conveniente para possibilitar ao leitor do trabalho uma avaliação acerca do alcance e da validade dos resultados apresentados. Mas constata-se também que em muitos desses trabalhos as seções destinadas à introdução e à fundamentação metodológica ocupam um espaço maior que o dedicado à análise e discussão dos resultados. Também se verifica em alguns dos trabalhos uma extensa revisão bibliográfica. O que pode, por um lado, ser entendido como contribuição interessante para contextualizar o trabalho, mas, por outro, como elemento capaz de dificultar o processo de redução transcendental fenomenológica, já que este que requer a "colocação entre parênteses" de qualquer concepção prévia acerca dos fenômenos. Assim, o que cabe é a análise mais detida dos resultados com vistas a verificar a adequação dessas técnicas de coleta de dados às pesquisas fenomenológicas.

\section{Conclusão}

O método fenomenológico é reconhecido como potencialmente importante para a investigação em Administração e um de seus campos em que se mostra mais adequado é o do empreendedorismo. De fato, poucos procedimentos metodológicos mostram-se tão ricos para possibilitar o conhecimento da experiência vivida dos empreendedores, que constitui um dos aspectos mais fundamentais do empreendedorismo. Como o método fenomenológico possibilita desvelar os fenômenos, faz com que a ação empreendedora seja conhecida pelo "lado de dentro", do ponto de vista do próprio empreendedor. Assim, os resultados obtidos nas pesquisas realizadas segundo esse enfoque possibilitam a contemplação do fenômeno empreendedor em sua essência.

A produção científica acerca do empreendedorismo construída graças à utilização do método 
fenomenológico, no entanto, ainda é muito insipiente no Brasil. Como indicam os resultados aqui obtidos, poucos têm sido os trabalhos desenvolvidos sob esse enfoque. Ou que foram apresentados em eventos nacionais e em periódicos que divulgam a produção científica referente ao empreendedorismo. Por outro lado, a participação sistemática dos mesmos autores em muitos desses trabalhos indica como ainda é restrita a comunidade de pesquisadores dispostos a realizar pesquisas sob esse enfoque.

A pequena quantidade de pesquisas fenomenológicas sobre empreendedorismo deve-se principalmente à hegemonia do paradigma positivista no campo da Administração, que se manifesta desde sua a constituição como disciplina científica. Para muitos pesquisadores cuja formação se deu nos moldes clássicos, os procedimentos de natureza quantitativa são os únicos adequados para a investigação em Administração. Assim, a maior dificuldade para execução de pesquisas fenomenológicas não está na capacitação técnica dos pesquisadores, mas na adoção de uma atitude científica que privilegie mais a compreensão dos fenômenos em sua essência do que em suas manifestações particulares.

Torna-se necessário, portanto, garantir que o ensino dos métodos e técnicas de pesquisa qualitativa se efetive nos cursos de Administração, não apenas em nível de mestrado ou doutorado, mas também de graduação. Isso porque o aprendizado acerca dos fenômenos administrativos não pode ignorar a sua forma de apreensão. Se o estudante se iniciar no aprendizado da ciência administrativa admitindo que só o que pode ser mensurado é verdadeiro, serão grandes as dificuldades para adoção do enfoque fenomenológico num eventual trabalho científico.

Importante papel cabe, portanto, às instituições empenhadas na realização de pesquisas em Administração. Assim, recomenda-se a ampla discussão acerca dos fundamentos ontológicos, epistemológicos e metodológicos da Administração. Conviria que os pesquisadores ao optarem pela realização de pesquisas científicas dispusessem de sólidos conhecimentos acerca da natureza do objeto da Administração, dos limites ao seu conhecimento e da adequação dos procedimentos metodológicos aos seus propósitos. Dessa forma ter-se-ia provavelmente não apenas a ampliação da quantidade de pesquisas de cunho qualitativo, mas também a realização de pesquisas quantitativas com maior rigor.

\section{REFERÊNCIAS}

ANDERSON, Alistair R.; STARNAWSKA, Marzena.

Problems of definition, description and meaning. The

International Journal of Entrepreneurship and

Innovation, v. 9, n. 4, Nov. 2008, p. 221-230.

BARDIN, Laurence. Analise de conteúdo. [S.I.]: Edições 70, 1997.

BATTISTELLA, Luciana Flores et al. A experiência vivida da falência: o ser-falido e suas múltiplas derrotas. In: XIV SEMINÁRIOS DE ADMINISTRAÇAO - SEMEAD. São

Paulo, 2011. Anais... São Paulo: SEMEAD, 2011.

BAZANINI, Roberto; ZANUTO, Renato. Estratégias e geração de vantagem competitiva no mercado de veículos off road: análise fenomenológica do lançamento do modelo Ford Ecosport no Brasil. Revista Brasileira de Marketing, São Paulo, v . 10, n. 1, jan.-abr., 2006. Disponível em: http://www.revistabrasileiramarketing.org/ ojs-2.2.4/index.php/remark/article/viewFile/2203/pdf_44. Acesso em: $20 \mathrm{dez} .2011$.

BERGLUND, Henrik. Researching entrepreneurship as lived experience. In: NEERGAARD, Helle; ULHØI, John

$P$. Handbook of qualitative research methods in entrepreneurship. Cheltenham: Edward Elgar, 2007. p. 75-93.

BOAVA, Diego Luiz Teixeira; MACEDO, Fernanda Maria Felício. Estudo sobre a essência do empreendedorismo. In: XXX ENCONTRO DA ASSOCIAÇÃO NACIONAL DE PÓS-GRADUAÇÃO E PESQUISA EM ADMINISTRAÇÃO - EnANPAD. Salvador, 2006. Anais... Rio de Janeiro: ANPAD, 2006.

BOAVA, Diego Luiz Teixeira; MACÊDO, Fernanda Maria Felício; LOPES, Paulo da Costa. Percepções de empresários incubados face ao contexto empreendedor. In: XXX ENCONTRO DA ASSOCIAÇÃO NACIONAL DE PÓS-GRADUAÇÃO E PESQUISA EM ADMINISTRAÇÃO - EnANPAD. Salvador, 2006. Anais... Salvador, ANPAD, 2006. 
BOAVA, Diego Luiz Teixeira; MACEDO, Fernanda Maria Felício. Dimensões epistemológicas da pesquisa em empreendedorismo. In: XXXII ENCONTRO DA ASSOCIAÇÃO NACIONAL DE PÓS-GRADUAÇÃO E PESQUISA EM ADMINISTRAÇÃO - EnANPAD. Rio de Janeiro, 2008. Anais... Rio de Janeiro, ANPAD, 2008.

BOAVA, Diego Luiz Teixeira; MACÊDO, Fernanda Maria Felício. Contribuições da fenomenologia para os estudos organizacionais. In: VI ENCONTRO DE ESTUDOS ORGANIZACIONAIS DA ASSOCIAÇÃO NACIONAL DE PÓS-GRADUAÇÃO E PESQUISA EM ADMINISTRAÇÃO - EnANPAD. Florianópolis, 2010. Anais... Florianópolis, 2010.

BRENTANO, Franz Clemens. Descriptive psychology. London: Routledge, 1995.

CARVALHO, José L. F; VERGARA, Sylvia. C. A Fenomenologia e a pesquisa dos espaços de serviços.

Revista de Administração de Empresas, São Paulo, v. 42, n. 3, p. 78-91, jul.-set.2002.

\section{CHAVES, Henrique Q. Educação em}

empreendedorismo: a potencialização de negócios por meio do desenvolvimento de competências do empreendedor. Dissertação de Mestrado (Administração). Programa de PósGraduação em Administração, UFPE, 2006.

COLAIZZI, Paul. Learning and existence. In: VALLED, R. S.; KING, M.(Ed.). Existencial: phenomenological alternatives for psychology. New York: Oxford Press, 1978.

COOPER, Donald R.; SCHINDLER, Pamela S. Métodos de pesquisa em administração. 7. ed. São Paulo: Bookman, 2003.

COPE, Jason. Researching entrepreneurship through phenomenological inquiry: philosophical and methodological issues. International Small Business Journal, USA, v. 23, n. 2, p. 163-189, April, 2005.

DAVIDSON, P. Research entrepreneurship. New York: Springer, 2004.

DENZIN, Norma K, LINCOLN, Yvonna S. Introduction: Entering the field of qualitative research. In: DENZIN, Norma K.; LINCOLN, Yvonna S. (Ed.). Handbook of Qualitative Research, Thousand Oaks: Sage Publications, 1994.
DURKHEIM, Émile. As regras do método sociológico.

2. ed. São Paulo: Martins Fontes, 1999

EHRICH. Lisa C. Revisiting phenomenology: its potential for management research. British Academy of Management Conference: Challenges or organizations in global markets, 13-15 set. 2005. Said Business School, Oxford University.

FILION, Louis Jacques et al. The future of entrepreneurship research: results of a research workshop with invited speakers and discussants at the International Council for Small Business World Conference in Halifax. International Journal of Entrepreneurship \& Small Business, USA, v. 11, n. 2, p. 105- 120, 2010.

GIBSON, Sharon K.; HANES, Lisa A. The contribution of phenomenology to HRD research. Human Resource Development Review, USA, v. 2, n. 2, 2003.

GIL, Antonio Carlos. O método fenomenológico na pesquisa em administração. Caderno de Pesquisa e Pós-Graduação IMES, São Caetano do Sul, n. 8. $1^{\circ}$ Semestre, 2003.

GIORGI, Amadeo. The phenomenological psychology of learning and the verbal learning tradition. In: GIORGI, A.

Phenomenology and pshycological research. Pittsburg: Duquesne University, 1985.

HEIDEGGER, Martin. The phenomenological method of investigation. In: MOONEY, Tim; MORAN, Dermont. The phenomenological reader. London: Routledge, 2002.

HEIDEGGER, Martin. Introduction to

phenomenological research. Bloomington: Indiana University Press, 2005.

HUSSERL, Edmund. A ideia da fenomenologia. Lisboa: Edições 70, 1986.

JASPERS, Karl. Psicopatologia geral: psicologia compreensiva, explicativa e fenomenologia. 2. ed. Rio de Janeiro: Atheneu, 1979.

JOHNSTONE, Bruce A. Ethnographic methods in entrepreneurship research. In: NEERGARD Helle; ULHOI, John Parm (Ed.). Handbook of Qualitative Research. Cheltenham: Edward Elgar Publishing, 2007. 
KELLEY, Donna J.; SINGER, Slavica; HERRINGTON, Mike. 2011 global report. London: The Global Entrepreneurship Monitor, 2012. Disponível em: <www. gemconsortium.org/docs/download/2201>. Acesso em: 2 jul. 2012.

LEITCH, Claire. M. An action research approach to entrepreneurship. In: NEERGARD Helle; ULHOI, John Parm. (Ed.). Handbook of Qualitative Research. Cheltenham: Edward Elgar Publishing, 2007.

\section{LOWDER, Tim B. Choosing a methodology for} entrepreneurial research: a case for qualitative research in the study of entrepreneurial success factors. 29 maio 2009. Disponível em: <http://ssrn.com/ abstract $=1413015>$. Acesso em: 20 out. 2011.

MACEDO. Fernanda Maria Felício; ICHIKAWA; Elisa Yoshie; BOAVA Diego Luiz Teixeira. O esquema típico-ideal na pesquisa em empreendedorismo. In: EGEPE - ENCONTRO DE ESTUDOS SOBRE EMPREENDEDORISMO E GESTÃO DE PEQUENAS EMPRESAS. 5. 2008, São Paulo. Anais... São Paulo, 2008.

MACÊDO, Fernanda Maria Felício; BOAVA, Diego Luiz Teixeira. Relação incubadora de empresas e ação empreendedora. Revista Ciências Administrativas, São Paulo, v. 15, n. 1. 2009. p. 221-240, jan.-jun. 2009. Disponível em: <http://www.unifor.br/index. php?option $=$ com_content $\&$ view $=$ article $\& \mathrm{id}=463 \&$ Item $\mathrm{id}=214>$. Acesso em: $20 \mathrm{dez} .2011$.

MAIRING, Philipp. Qualitative Inhaltsanalyse, Grundlagen und Techniken. 8. ed. Weinheim: Beltz, 2003.

MÄKELÄ, Markus; TURCAN, Romeo V. Building theory from data in field of entrepreneurship. In: CONFERENCE ON ENTREPRENEURSHIP AND INNOVATION IN A UNITED EUROPE, Amsterdam, Netherlands, 2005.

McKENZIE, Brian. Techniques for colecting verbal histories. In: NEERGARD Helle; ULHOI, John Parm. (Ed.). Handbook of Qualitative Research. Cheltenham: Edward Elgar Publishing, 2007.

MERLEAU-PONTY, Maurice. Fenomenologia da percepção. 3. ed. São Paulo: Martins Fontes, 2006.
MOREIRA, Daniel A. O método fenomenológico na pesquisa. São Paulo: Pioneira Thomson, 2002.

NEERGARD Helle; ULHOI, John Parm. (Ed.). Handbook of Qualitative Research. Cheltenham: Edward Elgar Publishing, 2007.

OLIVEIRA, Marcos André Farias de. O Saber a partir de quem sabe: elementos para (re)pensar a formação em empreendedorismo. In: EGEPE - ENCONTRO DE ESTUDOS SOBRE EMPREENDEDORISMO E GESTÃO DE PEQUENAS EMPRESAS. 5. 2008, São Paulo,

Anais... São Paulo, 2008.

PAIVA JÚNIOR, Fernando. G.; MELLO, Sergio C. B. Pesquisa qualitativa nos estudos organizacionais: contribuições fenomenológicas de Alfred Schütz. Organizações em Contexto, São Paulo, v. 4, p. 24-48, 2008.

PAIVA JÚNIOR, Fernando Gomes de; MELLO, Sérgio Carvalho Benício de; GONÇALVES, Carlos Alberto. Empreendedorismo e relacionamento: um composto de confiança e adaptabilidade. In: EGEPE - ENCONTRO DE ESTUDOS SOBRE EMPREENDEDORISMO E GESTÃO DE PEQUENAS EMPRESAS. 4. 2005, Curitiba, Anais... Curitiba, p. 159-168, 2005.

PAIVA JÚNIOR, Fernando Gomes.

O Empreendedorismo na ação de empreender: uma análise sob o enfoque da fenomenologia sociológica de Alfred Schütz. Tese de Doutorado (Administração) CEPEAD, Faculdade de Ciências Econômicas - FACE, UFMG, Belo Horizonte, 2004.

RODRIGUES, Paulo Henrique Mendonça; VIEIRA, Flávia Regina Czarneski. A mediação sociocultural na ação empreendedora: por um plano de vida que antecede o plano de negócios. XXVIII ENCONTRO DA ASSOCIAÇÃO NACIONAL DE PÓS-GRADUAÇÃO E PESQUISA EM ADMINISTRAÇÃO - ENANPAD, 2004, Curitiba. Anais... Curitiba, 2004.

SANDERS, Patrice. Phenomenology: a new way of viewing organizational research, Academy of Management Review, USA, v. 7, n. 3, p. 353-60, 1982.

SARTRE, Jean Paul. O ser e o nada: ensaio de ontologia fenomenológica. Petrópolis: Vozes, 1997. 
SCHUMPETER, Joseph. History of economic analysis. New York: Oxford University Press, 1954.

SILVA, Juliana Vieira Almeida. A relação trabalho e família de mulheres empreendedoras. Perspectivas Contemporâneas, Campo Mourão, v. 1, n. 1, jan.-jul., 2006. Disponível em: <http://revista.grupointegrado.br/ revista/index.php/perspectivascontemporaneas/article/ viewFile/355/163 > . Acesso em: 22 dez. 2011.

SILVEIRA, Rogério Z.; FISCHER, Cleiton; OLIVIER, Marilene. A fenomenologia como método de pesquisa: uma análise a partir dos trabalhos publicados nos principais eventos e revistas nacionais em administração 1997 a 2008. In: XXXIV ENCONTRO DA ASSOCIAÇÃO NACIONAL DE PÓS-GRADUAÇÃO E PESQUISA EM ADMINISTRAÇÃO - ENANPAD, 2010, Rio de Janeiro.

Anais... Rio de Janeiro, 2010.

TEIXEIRA, Marco. A. P.; GOMES, William B. Autonomous career change among professionals: an empirical phenomenological study. Journal of Phenomenological Psychology, USA, v. 3, n.1, p. 78-96, 2000.

THIRY-CHERQUES, Hermano. Pesquisa qualitativa em administração: teoria e prática. Rio de Janeiro: Editora FGV, 2004.

THOMPSON, Craig J.; LOCANDER, William B.; POLLIO, Howard R. Putting consumer experience back into consumer research: the philosophy and method of existential phenonenology. Journal of Consumer Reseach, USA, v. 16, p. 133-146, 2009.

VAN KANN, Adrian. Phenomenological analysis: exemplified by a study of the experience of really feeling understood. Journal of Individual Psychology, USA, v. 15, p. 66-72, 1959.

VAN MANEN, Max. Researching lived experience: human science for an action sensitive pedagogy. New York: State University of New York Press, 1990.

VIEIRA, Almir Martins. Questões hermenêuticas em estudos organizacionais: um olhar sobre a fenomenologia e sobra a etnografia. In: XXX ENCONTRO DA ASSOCIAÇÃO NACIONAL DE PÓS-GRADUAÇÃO E PESQUISA EM ADMINISTRAÇÃO - ENANPAD, 2009, São Paulo. Anais... São Paulo, 2008.
VILELA, Lamounier Erthal. Feiras setoriais em arranjos produtivos locais como lócus de inovação $e$ empreendedorismo: o caso da Fevest de Nova Friburgo, RJ. Revista Administração em Diálogo, São Paulo, v. 12, n. 2, 2010. Disponível em: < http://revistas.pucsp.br/ index.php/rad/issue/view/286/showToc >. Acesso em: 16 dez. 2011.

ZIKMUND, William G. Business research methods. 7. ed. Thomson South-Western, 2003. 